\title{
Intravitreal injection of ranibizumab using a pro re nata regimen for age-related macular degeneration and vision-related quality of life
}

This article was published in the following Dove Press journal:

Clinical Ophthalmology

4 September 2014

Number of times this article has been viewed

\section{Maiko Inoue \\ Akira Arakawa \\ Shin Yamane \\ Kazuaki Kadonosono \\ Department of Ophthalmology, Yokohama City University Medical \\ Center, Yokohama, Japan}

Correspondence: Maiko Inoue 4-57 Urafune-cho, Minami-ku, Yokohama, Kanagawa 232-0024, Japan

Fax +81452538490

Tel +8I $4526 \mid 5656$

Email maicoo@urahp.yokohama-cu.ac.jp
Background: The purpose of this study was to assess visual function and vision-related quality of life after intravitreal injection of ranibizumab (IVR) using a pro re nata regimen for the treatment of age-related macular degeneration.

Methods: A prospective study of 54 eyes in 54 patients scheduled to undergo IVR for the treatment of exudative age-related macular degeneration was performed. A self-administered, 25-item National Eye Institute Visual Function Questionnaire (NEI VFQ-25) was completed before and 3 and 12 months after the initial IVR treatment. We evaluated logMAR visual acuity and NEI VFQ-25 scores preoperatively and postoperatively. Further, associations between the changes in NEI VFQ-25 scores and patient characteristics were investigated at 12 months.

Results: Postoperative best-corrected visual acuity improved significantly when compared with the preoperative visual acuity throughout the 12 -month period $(P<0.05$ at 3 and 12 months, respectively). On the other hand, IVR treatment significantly improved the postoperative NEI VFQ-25 mean composite score at both 3 and 12 months $(P<0.05$, respectively). Better visual acuity at 12 months was associated with a greater improvement in NEI VFQ-25 score at 12 months $(P<0.05)$.

Conclusion: IVR was well tolerated and improved vision in these patients with age-related macular degeneration, as evaluated at one-year follow-up examinations. IVR also enabled good subjective perception, as indicated by higher composite NEI VFQ-25 scores. Maintaining good visual acuity may be an important factor for improving vision-related quality of life.

Keywords: age-related macular degeneration, ranibizumab, intravitreal injection, vascular endothelial growth factor, vision-related quality of life

\section{Introduction}

Age-related macular degeneration (AMD) is the leading cause of severe irreversible vision loss in older adults. ${ }^{1,2}$ Because of the rapidly aging population, the number of persons with AMD is expected to continue to increase in the future. ${ }^{3}$ Severe vision loss in patients with AMD is caused by development of choroidal neovascularization $(\mathrm{CNV}){ }^{4}$ The quality of life of patients with AMD is reportedly lower than that of normal subjects. ${ }^{5}$

Recently, agents inhibiting the actions of vascular endothelial growth factor have been used to inhibit CNV in patients with AMD. Ranibizumab (Lucentis ${ }^{\circledR}$; Novartis Pharma AG, Basel, Switzerland and Genentech, Inc., South San Francisco, CA, USA) is a recombinant humanized anti-vascular endothelial growth factor antibody fragment targeting all isoforms of vascular endothelial growth factor. ${ }^{6}$ Intravitreal injection of ranibizumab (IVR) administered as needed has been well tolerated in patients with AMD. ${ }^{7}$ 
Evaluating the extent to which IVR improves patient quality of life is of much interest. Although several characteristics of IVR, such as visual outcomes, morphological changes assessed using optical coherence tomography, and complications, have been thoroughly evaluated, the influence of IVR administered pro re nata on patient quality of life has not yet been investigated. On the other hand, the National Eye Institute has developed a 25-item National Eye Institute Visual Function Questionnaire (NEI VFQ-25) to measure patients' subjective perceptions. ${ }^{8}$ This questionnaire has been widely used to assess vision-related quality of life in patients with eye diseases such as cataracts, ${ }^{9}$ glaucoma, ${ }^{10}$ AMD,${ }^{11}$ macular hole, ${ }^{12}$ proliferative diabetic retinopathy, ${ }^{13}$ and rhegmatogenous retinal detachment. ${ }^{14}$

The present study evaluated the effect of IVR for the treatment of AMD on visual function and vision-related quality of life using the NEI VFQ-25 questionnaire. Factors influencing changes in NEI VFQ-25 scores were also investigated.

\section{Materials and methods}

A prospective study was designed to assess visual function and vision-related quality of life after IVR using a pro re nata regimen for the treatment of AMD. All the patients were treated at the Yokohama City University Medical Center between October 2011 and September 2012. The study was conducted according to the principles of the Declaration of Helsinki and was approved by our institution's ethics committee. Informed consent was obtained from all the eligible patients.

Inclusion criteria were: presence of $\mathrm{CNV}$ as a result of AMD, diagnosed on the basis of clinical, angiographic and spectral-domain optical coherence tomography findings; availability for follow-up for $\geq 12$ months after the first intravitreal administration of ranibizumab; and best-corrected visual acuity (BCVA) of 20/400 or better at baseline.

Because retinal angiomatous proliferation can occur in $4.5 \%$ of Japanese patients with AMD,${ }^{15}$ patients with this condition were not included in the study. Patients who stopped attending the hospital, those who developed exudative AMD in the contralateral eye, and those who received cataract surgery in the study eye or the contralateral eye during the follow-up period were also excluded.

All the patients received three initial monthly injections of ranibizumab $0.5 \mathrm{mg} / 0.05 \mathrm{~mL}$. After the induction phase, the intravitreal injections were administered if any of the following changes were observed: presence of visual acuity loss $>0.2 \log$ MAR (logarithm of the minimum angle of resolution) vision; persistent or new hemorrhage; persistent or recurrent subretinal or intraretinal fluid accumulation; or fluctuation of pigment epithelial detachment as assessed using spectral-domain optical coherence tomography (Cirrhus high-definition OCT; Carl Zeiss, Dublin, CA, USA) at the monthly visit.

The NEI VFQ-25 was self-administered before and 3 and 12 months after the initial IVR treatment. The NEI VFQ-25 contains 25 questions measuring visual function. Each question is rated on a scale of $1-12$; the questions concern general health, general vision, ocular pain, near activities, distance activities, social functioning, mental health, role difficulties, dependency, driving, color vision, and peripheral vision. Each subscale is then transformed to a 0-100 scale, with higher scores indicating better subjective visual function. The NEI VFQ-25 composite score is calculated as the mean score of all the subscales, excluding the general health item. ${ }^{8}$ The Japanese version of the NEI VFQ-25 used in this study has been previously assessed for reliability and validity. ${ }^{9}$

The main outcome measures were postoperative BCVA and NEI VFQ-25 scores. The BCVA was converted to $\log$ MAR equivalents for statistical analysis. Further, we used stepwise multiple regression analyses and the Spearman rank correlation test to evaluate the correlations between patient characteristics, namely, age, sex, visual acuity of the contralateral eye, visual acuity of the study eye at baseline and postoperatively, differences in visual acuity, type of AMD classified into classic $\mathrm{CNV}$, occult $\mathrm{CNV}$, and polypoidal choroidal vasculopathy, number of injections, and differences between preoperative and postoperative NEI VFQ-25 scores at 12 months after IVR.

The Student's $t$-test was used to compare NEI VFQ-25 scores or visual acuity between the baseline value and the value at 3 and 12 months. A $P$-value $<0.05$ was considered to be statistically significant.

\section{Results}

Fifty-four eyes completed 3 months of follow-up. During the follow-up period, four patients stopped attending the outpatient clinic, and one patient developed AMD in the contralateral eye. Finally, the outcomes in the remaining 49 eyes of 49 patients were completed at 12 months follow-up. Baseline patient demographic and clinical characteristics are presented in Table 1. Of the 54 patients included in the series, 35 patients were men and 19 were women. The patients ranged in age from 52 to 86 (mean $73.8 \pm 7.1$ ) years. Thirteen patients (24.1\%) had classic CNV, 18 (33.3\%) had occult $\mathrm{CNV}$, and the remaining 23 (42.6\%) had polypoidal choroidal vasculopathy. Table 2 presents a comparison of 
Table I Baseline characteristics

\begin{tabular}{ll}
\hline Number of patients & 54 \\
Male (\%) & $35(64.8)$ \\
Female (\%) & $19(35.2)$ \\
Age, mean \pm SD, year (range) & $73.8 \pm 7.1(52-86)$ \\
Preoperative logMAR visual acuity in & $0.43 \pm 0.33$ \\
study eye, mean \pm SD & \\
Preoperative logMAR visual acuity in & $0.11 \pm 0.42$ \\
fellow eye, mean \pm SD & \\
Lesion type & \\
$\quad$ Classic CNV (\%) & $13(24.1)$ \\
Occult with no classic CNV (\%) & $18(33.3)$ \\
Polypoidal choroidal vasculopathy (\%) & $23(42.6)$ \\
Mean number of injections & $4.1 \pm 2.0$ \\
\hline
\end{tabular}

Abbreviations: CNV, choroidal neovascularization; logMAR, logarithm of the minimum angle of resolution; SD, standard deviation.

the characteristics according to AMD subtype. The mean $\log$ MAR BCVA at baseline in patients with classic CNV was significantly higher than that of occult $\mathrm{CNV}$ and polypoidal choroidal vasculopathy $(P=0.048)$.

The mean logMAR BCVA values at baseline and at 3 and 12 months after IVR treatment were $0.43 \pm 0.33,0.32 \pm 0.37$, and $0.30 \pm 0.36$, respectively. Postoperative BCVA improved significantly, compared with preoperative visual acuity, throughout the 12 -month period $(P<0.001$ and $P=0.034$ at 3 and 12 months, respectively; Figure 1).

The mean $\log$ MAR BCVA at baseline was $0.59 \pm 0.29$ in patients with classic CNV, $0.40 \pm 0.30$ in patients with occult $\mathrm{CNV}$, and $0.36 \pm 0.35$ in patients with polypoidal choroidal vasculopathy. The mean $\log$ MAR BCVA values at 3 and 12 months after the first IVR treatment were $0.38 \pm 0.39$ and $0.31 \pm 0.40$, respectively, in patients with classic $\mathrm{CNV}$, $0.32 \pm 0.30$ and $0.34 \pm 0.31$, respectively, in patients with occult $\mathrm{CNV}$, and $0.30 \pm 0.41$ and $0.27 \pm 0.38$, respectively, in patients with polypoidal choroidal vasculopathy. In the patients with

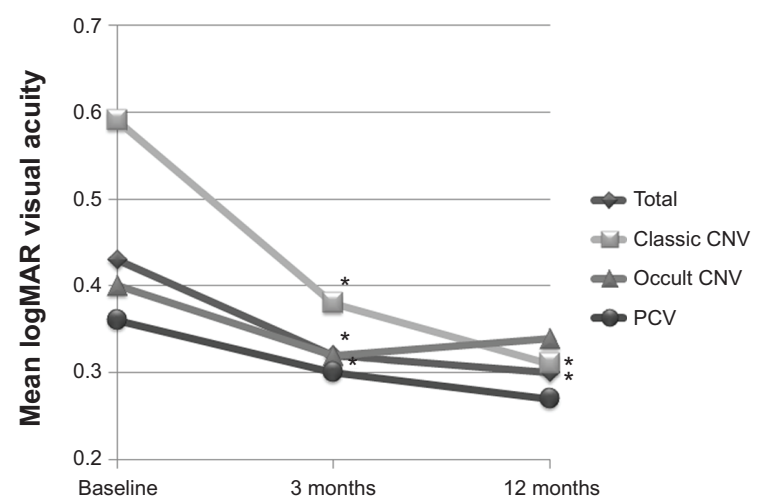

Figure I Visual acuity at baseline and at 3 and 12 months after the initial injection. Notes: In all the patients and in patients with classic CNV, the post-injection bestcorrected visual acuity at 3 and 12 months was significantly improved, compared with the baseline visual acuity ( $* P<0.05$, respectively). In eyes with occult $C N V$ or polypoidal choroidal vasculopathy, the post-injection best-corrected visual acuity was well maintained, compared with the baseline visual acuity, throughout the 12 month follow-up.

Abbreviations: CNV, choroidal neovascularization; PCV, polypoidal choroidal vasculopathy.

classic CNV, a significant improvement in mean logMAR BCVA was observed, compared with the baseline value, with improved visual acuity sustained throughout the 12-month period ( $P=0.004$ and $P=0.030$, respectively). In patients with occult $\mathrm{CNV}$, post-injection BCVA at 3 months, but not at 12 months, was significantly improved when compared with the value at baseline $(P=0.016$ and $P=0.299$ at 3 and 12 months, respectively). On the other hand, in the patients with polypoidal choroidal vasculopathy, no significant difference in mean BCVA was observed at any of the time points of evaluation when compared with the baseline value, although BCVA tended to improve ( $P=0.104$ and $P=0.218$ at 3 and 12 months, respectively; Figure 1).

Figure 2 shows the preoperative and postoperative mean subscale and composite questionnaire scores. Postoperative

Table 2 Comparison of characteristics for subtypes of AMD

\begin{tabular}{|c|c|c|c|c|c|}
\hline & & $\begin{array}{l}\text { Classic CNV } \\
(n=13)\end{array}$ & $\begin{array}{l}\text { Occult CNV } \\
(n=18)\end{array}$ & $\operatorname{PCV}(n=23)$ & P-value* \\
\hline Age, years, mean $\pm S D$ (range) & & $72.8 \pm 7.0(59-84)$ & $76.7 \pm 5.5(62-83)$ & $72.1 \pm 7.7(52-86)$ & 0.073 \\
\hline Numbers of males/females & & $9 / 4$ & $15 / 3$ & $11 / 12$ & 0.060 \\
\hline Baseline logMAR visual acuity, mean \pm SD & & $0.59 \pm 0.29$ & $0.40 \pm 0.30$ & $0.36 \pm 0.35$ & 0.048 \\
\hline Proportion of patients with changes in the BCVA & 3 months & $6 / 7 / 0$ & $2 / 15 / 1$ & $3 / 19 / 1$ & 0.117 \\
\hline $\begin{array}{l}\text { of logMAR } 0.3 \text { or more (improvement/maintained/ } \\
\text { deterioration) }\end{array}$ & 12 months & $7 / 3 / 1$ & $1 / 14 / 0$ & $2 / 19 / 2$ & 0.001 \\
\hline Number of injections at 12 months, mean \pm SD & & $3.3 \pm 1.3$ & $4.0 \pm 1.3$ & $4.7 \pm 2.4$ & 0.248 \\
\hline Change in NEI VFQ-25 composite scores at 3 months & & $3.88 \pm 9.64$ & $-0.36 \pm 7.78$ & $6.86 \pm 12.2$ & 0.318 \\
\hline Change in NEI VFQ-25 composite scores at 12 months & & $14.6 \pm 25.4$ & $5.27 \pm 24.1$ & $4.06 \pm 17.8$ & 0.386 \\
\hline
\end{tabular}

Notes: *Characteristics for each AMD types were compared using the Kruskal-Wallis test. A chi-square test was used to compare the proportion of improvement or deterioration in visual acuity.

Abbreviations: AMD, age-related macular degeneration; SD, standard deviation; CNV, choroidal neovascularization; PCV, polypoidal choroidal vasculopathy; NEI VFQ-25, 25-item National Eye Institute Visual Function Questionnaire; logMAR, logarithm of the minimum angle of resolution; BCVA, best-corrected visual acuity. 


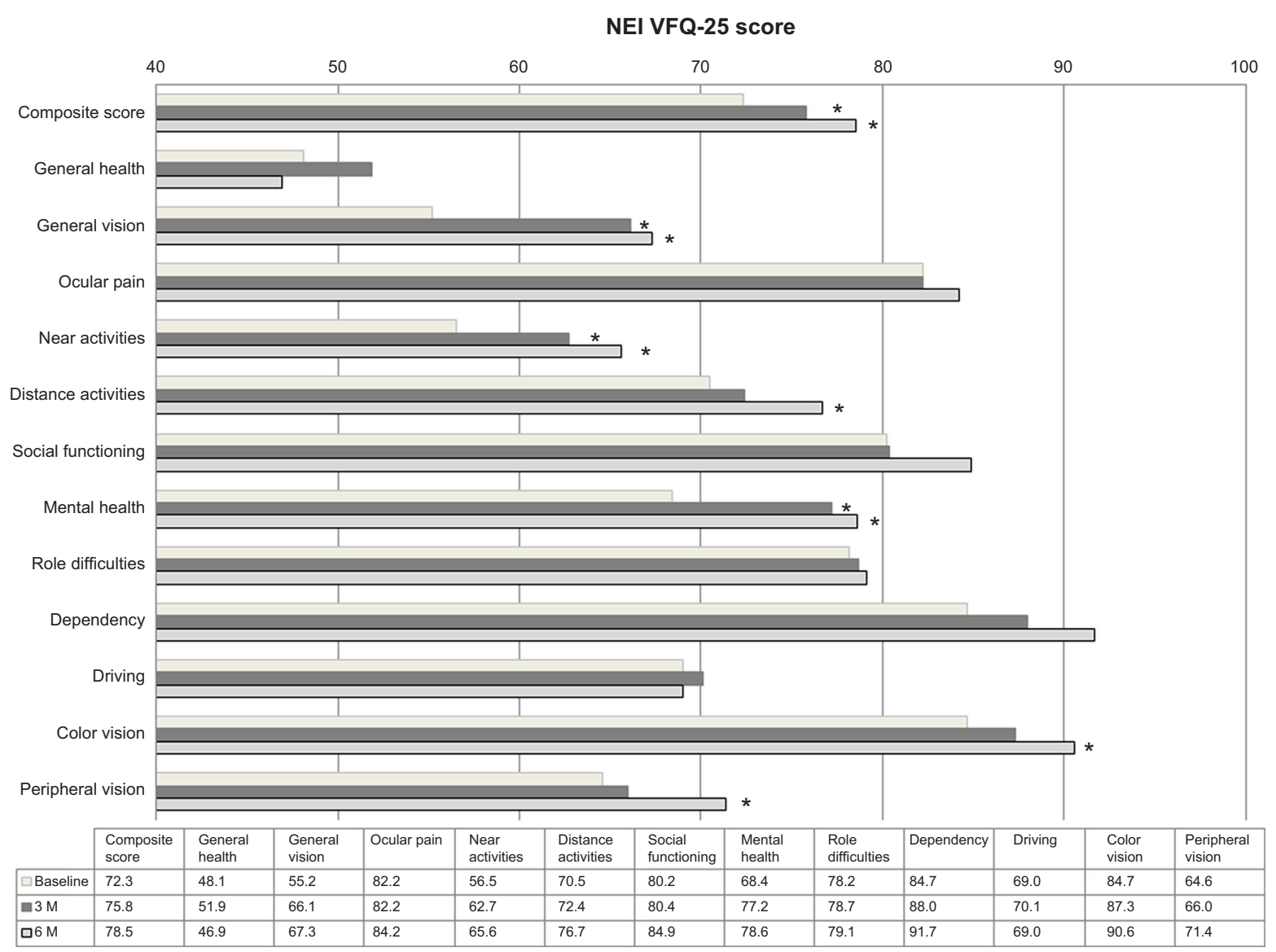

Figure 2 Comparison of mean subscale and composite scores.

Notes: At both 3 and 12 months, the post-injection NEI VFQ-25 mean composite score was significantly higher than the preinjection score. The NEI VFQ-25 scores for three of the 12 subscales, ie, general vision, near activities, and mental health, were significantly improved at 3 months. Furthermore, the NEI VFQ- 25 scores for six of the 12 subscales, ie, general vision, near activities, distance activities, mental health, color vision, and peripheral vision, showed significant improvement at 12 months. $* P<0.05$. Abbreviations: NEI VFQ-25, 25-item National Eye Institute Visual Function Questionnaire; 3 M, 3 months; 12 M, 12 months.

NEI VFQ-25 mean composite scores at 3 and 12 months were significantly higher than the preoperative score $(P=0.006$ and $P=0.016$, respectively). At 3 months after initial IVR for treatment of AMD, significant improvements in NEI VFQ-25 scores were observed for three of the 12 subscales, ie, general vision, near activities, and mental health ( $P<0.001, P=0.015$, and $P<0.001$, respectively). Further, at 12 months after initial IVR for treatment of AMD, significant improvements in NEI VFQ-25 scores were observed for six of the 12 subscales, ie, general vision, near activities, distance activities, mental health, color vision, and peripheral vision $(P<0.001, P=0.022, P=0.021, P=0.009, P=0.038$, and $P=0.043$, respectively).

Table 3 shows the results of stepwise multiple regression analyses and the Spearman rank correlation test. Better visual acuity at 12 months was associated with better improvement of NEI VFQ-25 composite scores at 12 months $\left(R^{2}=0.123, P=0.041 ; \gamma=-0.288, P=0.045\right.$, respectively).

\section{Discussion}

Our study showed an excellent visual outcome at one-year follow-up after IVR treatment as needed for exudative AMD. Further, IVR treatment resulted in a higher postoperative NEI VFQ-25 mean composite score and higher scores for half of the subscales.

Some studies have confirmed that IVR for exudative AMD improves vision-related quality of life, as indicated by higher postoperative composite scores. ${ }^{16,17}$ However, these studies evaluated monthly IVR treatments, and the effectiveness of pro re nata treatment with regard to vision-related quality of life has not been studied. Further, to the best of our knowledge, no other published reports have investigated factors influencing changes in NEI VFQ-25 scores.

Although a statistically significant improvement in BCVA occurred after one year, this translated to only one line of improvement. Therefore, it might be surprising to see a 6.2 point improvement in composite score, especially considering that cataract surgery has been found to improve 
Table 3 Results of stepwise multiple regression analyses and the Spearman rank correlation test

\begin{tabular}{|c|c|c|c|c|c|c|}
\hline & \multicolumn{3}{|c|}{$\begin{array}{l}\text { Change in NEI VFQ-25 composite scores } \\
\text { at } 3 \text { months }\end{array}$} & \multicolumn{3}{|c|}{$\begin{array}{l}\text { Change in NEI VFQ- } 25 \text { composite scores } \\
\text { at } 12 \text { months }\end{array}$} \\
\hline & $\begin{array}{l}\text { Multiple } \\
\text { regression } \\
\text { analysis } P \text {-value }\end{array}$ & $\begin{array}{l}\text { Univariate } \\
\text { analysis } \\
P \text {-value }\end{array}$ & $\gamma$ & $\begin{array}{l}\text { Multiple } \\
\text { regression } \\
\text { analysis } P \text {-value }\end{array}$ & $\begin{array}{l}\text { Univariate } \\
\text { analysis } \\
P \text {-value }\end{array}$ & $\gamma$ \\
\hline Age & & 0.206 & -0.175 & & 0.700 & -0.104 \\
\hline Sex & & 0.395 & 0.118 & & 0.478 & 0.056 \\
\hline logMAR BCVA at baseline & & 0.333 & -0.134 & & 0.136 & -0.216 \\
\hline logMAR BCVA at 3 (or 12) months & 0.096 & 0.161 & -0.193 & 0.041 & 0.045 & -0.288 \\
\hline Improvement of visual acuity & & 0.331 & -0.135 & & 0.32 & -0.145 \\
\hline logMAR BCVA of fellow eye & 0.097 & 0.286 & 0.148 & & 0.587 & -0.08 \\
\hline Presence/absence of classic CNV & & 0.955 & 0.008 & 0.154 & 0.177 & 0.196 \\
\hline Presence/absence of occult CNV & 0.020 & 0.044 & -0.275 & & 0.747 & -0.047 \\
\hline Presence/absence of PCV & & 0.062 & 0.216 & & 0.411 & -0.12 \\
\hline Number of injections & - & - & - & & 0.686 & -0.059 \\
\hline
\end{tabular}

Abbreviations: BCVA, best-corrected visual acuity; CNV, choroidal neovascularization; PCV, polypoidal choroidal vasculopathy; NEI VFQ-25, 25-item National Eye Institute Visual Function Questionnaire; logMAR, logarithm of the minimum angle of resolution.

more than 15 points. ${ }^{9,18}$ We speculate that restoration of foveal morphology after IVR, which results in improvement of symptoms such as distortion and central scotoma, might be also related to improvement of vision-related quality of life, even if there was only slight improvement in visual acuity.

The patients exhibited significant improvements in general vision, near activities, mental health, and composite score at 3 months, and showed a further significant improvement in distance activities, color vision, and peripheral vision at 12 months. The mental health subscale includes how often patients worry, feel frustrated, feel out of control, and worry about doing things that will embarrass themselves or others. Therefore, not only an improvement in vision-related activities, but also mental stability induced by receiving IVR, may consequently contribute to a real improvement in patient comfort and provide ongoing benefits, resulting in an increase in vision-related subscales and mental scale scores.

Regarding factors related to vision-related quality of life, the improved visual acuity at 12 months was associated with a greater improvement in NEI VFQ-25 composite scores at 12 months. This finding suggests that maintaining good visual acuity during the maintenance phase is the most important factor for improving NEI-VFQ25 composite scores at 12 months. Because baseline visual acuity is closely correlated with final visual acuity, ${ }^{17}$ an earlier diagnosis and prompt treatment are recommended to achieve better postoperative subjective satisfaction.

The main limitation of the present study is its small sample size. Further studies with larger sample sizes and longer follow-up periods are needed for a more precise evaluation.
In conclusion, IVR was well tolerated and improved vision in patients with AMD, as evaluated at one-year follow-up examination. IVR used pro re nata also enables good subjective perception, as indicated by higher composite NEI VFQ-25 scores in patients with AMD. Maintaining better visual acuity may be an important factor for improving vision-related quality of life.

\section{Disclosure}

The authors report no conflicts of interest in this work.

\section{References}

1. Bressler NM, Bressler SB, Fine SL. Age-related macular degeneration. Surv Ophthalmol. 1988;32:375-413.

2. Bressler NM, Bressler SB, Congdon NG, et al. Potential public health impact of Age-Related Eye Disease Study results: AREDS report no. 11. Arch Ophthalmol. 2003;121:1621-1624.

3. Bressler NM. Age-related macular degeneration is the leading cause of blindness. JAMA. 2004;291:1900-1901.

4. Ferris FL 3rd, Fine SL, Hyman L. Age-related macular degeneration and blindness due to neovascular maculopathy. Arch Ophthalmol. 1984; 102:1640-1642.

5. Mangione CM, Lee PP, Pitts J, Gutierrez P, Berry S, Hays RD. Psychometric properties of the National Eye Institute Visual Function Questionnaire (NEI-VFQ). NEI-VFQ Field Test Investigators. Arch Ophthalmol. 1998;116:1496-1504.

6. Fung AE, Rosenfeld PJ, Reichel E. The International Intravitreal Bevacizumab Safety Survey: using the Internet to assess drug safety worldwide. Br J Ophthalmol. 2006;90:1344-1349.

7. Lalwani GA, Rosenfeld PJ, Fung AE, et al. A variable-dosing regimen with intravitreal ranibizumab for neovascular age-related macular degeneration: year 2 of the PrONTO Study. Am J Ophthalmol. 2009;148: 43-58.e1.

8. Mangione CM, Lee PP, Gutierrez PR, Spritzer K, Berry S, Hays RD. Development of the 25-item National Eye Institute Visual Function Questionnaire. Arch Ophthalmol. 2001;119:1050-1058.

9. Suzukamo Y, Oshika T, Yuzawa M, et al. Psychometric properties of the 25-item National Eye Institute Visual Function Questionnaire (NEI VFQ-25), Japanese version. Health Qual Life Outcomes. 2005;3:65. 
10. Hyman LG, Komaroff E, Heijl A, Bengtsson B, Leske MC. Treatment and vision-related quality of life in the early manifest glaucoma trial. Ophthalmology. 2005;112:1505-1513.

11. Maguire M. Baseline characteristics, the 25-item National Eye Institute Visual Functioning Questionnaire, and their associations in the Complications of Age-Related Macular Degeneration Prevention Trial (CAPT). Ophthalmology. 2004;111:1307-1316.

12. Hirneiss C, Neubauer AS, Gass CA, et al. Visual quality of life after macular hole surgery: outcome and predictive factors. Br J Ophthalmol. 2007;91:481-484.

13. Cusick M, SanGiovanni JP, Chew EY, et al. Central visual function and the NEI-VFQ-25 near and distance activities subscale scores in people with type 1 and 2 diabetes. Am J Ophthalmol. 2005;139:1042-1050.

14. Okamoto F, Okamoto Y, Hiraoka T, Oshika T. Vision-related quality of life and visual function after retinal detachment surgery. Am J Ophthalmol. 2008;146:85-90.
15. Maruko I, Iida T, Saito M, Nagayama D, Saito K. Clinical characteristics of exudative age-related macular degeneration in Japanese patients. Am J Ophthalmol. 2007;144:15-22.

16. Bressler NM, Chang TS, Fine JT, Dolan CM, Ward J. Improved vision-related function after ranibizumab vs photodynamic therapy: a randomized clinical trial. Arch Ophthalmol. 2009;127:13-21.

17. Suner IJ, Kokame GT, Yu E, Ward J, Dolan C, Bressler NM. Responsiveness of NEI VFQ-25 to changes in visual acuity in neovascular AMD: validation studies from two phase 3 clinical trials. Invest Ophthalmol Vis Sci. 2009;50:3629-3635.

18. To KG, Meuleners LB, Fraser ML, et al. The impact of cataract surgery on vision-related quality of life for bilateral cataract patients in Ho Chi Minh City, Vietnam: a prospective study. Health Qual Life Outcomes. 2014;12:16.
Clinical Ophthalmology

\section{Publish your work in this journal}

Clinical Ophthalmology is an international, peer-reviewed journal covering all subspecialties within ophthalmology. Key topics include: Optometry; Visual science; Pharmacology and drug therapy in eye diseases; Basic Sciences; Primary and Secondary eye care; Patient Safety and Quality of Care Improvements. This journal is indexed on

\section{Dovepress}

PubMed Central and CAS, and is the official journal of The Society of Clinical Ophthalmology (SCO). The manuscript management system is completely online and includes a very quick and fair peer-review system, which is all easy to use. Visit http://www.dovepress.com/ testimonials.php to read real quotes from published authors. 